\title{
Leadership vs. Challenges: Perceptions of School Principals from Jiangsu China
}

\author{
Xiaobo Yang \\ SuOn College, Canada
}

\author{
Carol Brayman \\ Ontario Principal Council
}

\begin{abstract}
Principals of middle schools and high schools in the province of Jiangsu, China, face significant challenges. Using the Ontario Principal Leadership Framework as a reference, this study examines the leadership competencies that the Chinese principals believe they would need to meet these challenges. This research aims at a deeper understanding of the role of the principal in student achievement, and is based on the principals' reflections on the Ontario Principal Leadership Framework combined with their experiences in education-related visitations and discussions during a three-week training program in Toronto. The two cultures, Chinese and Canadian, have evident similarities and diversities; comparison suggests how the different approaches might effect or influence student achievement. This study should help the organization of future training programs, inspiring educational development and improvement through international comparison.
\end{abstract}

\section{Introduction}

In September of 2009, a delegation of 81 principals and vice principals from middle schools and high schools of Jiangsu Province of China came to Toronto to participate in a leadership training program organized collaboratively by SuOn College and the Faculty of Education, York University.

SuOn College, established in Toronto in 2007, is an overseas training base of the Jiangsu Department of Education. The purpose of the program is to help Chinese school administrators to expand their vision and to learn from their Canadian colleagues through observing and understanding Canadian school administration and leadership systems.

In order to encourage the delegation to think critically about a principal's role and leadership development, SuOn College designed a research project called The Role of the Principal in
Leadership Development: A Comparison of Jiangsu and Ontario Perspectives. Forty members of the delegation voluntarily joined this study, submitted survey questionnaires, and 5 among them also agreed to face-to-face interviews. The research data and information are derived from these surveys and interviews. The following Table 1 is a summary of the background information relating to the 40 research participants.

Table 1. Information about the 40 participants

\begin{tabular}{|c|l|l|l|l|}
\hline \multicolumn{2}{|l|}{ Persons } & $\begin{array}{l}\text { High } \\
\text { school } \\
\text { K10-12 }\end{array}$ & $\begin{array}{l}\text { Middle } \\
\text { school } \\
\text { K7-9 }\end{array}$ & Sum \\
\hline \multirow{2}{*}{ Gender } & M & 28 & 9 & 37 \\
\cline { 2 - 5 } & $\mathrm{F}$ & 2 & 1 & 3 \\
\hline \multirow{3}{*}{ Birth era } & $70 s^{\prime}$ & 4 & 0 & 4 \\
\cline { 2 - 5 } & $60 s^{\prime}$ & 23 & 10 & 33 \\
\cline { 2 - 5 } & $50 s^{\prime}$ & 3 & 0 & 3 \\
\hline Position & Principa & 20 & 7 & 27 \\
\cline { 2 - 5 } & $\begin{array}{l}\text { Vice } \\
\text { Principa }\end{array}$ & 10 & 3 & 13 \\
\hline
\end{tabular}

With the Ontario Principal Leadership Framework [1] as a reference, the 40 research participants integrated their experience from the training program and their past practices and knowledge in China, and summarized their personal perspectives about the role of a principal and his/her leadership development. The researchers of the study are the coordinators of the SuOn College training program with a strong background of teaching, administration, training, and research in both Chinese and Canadian educational systems.

\section{Research Method}

This study is based on the perceptions, opinions, and interpretations of principals and vice principals from China regarding the role of principal in leadership development. Lincoln said: "individuals and groups made meaning based on their own 
experiential knowledge, rather than on an outsider's precise statistics, and that, in virtually any kind of social or programmatic context, individuals and groups would act on their own, internal, sense making and meaning-making knowledge processes rather than on our assertions of statistical rigor. They always chose their own socially-constructed, context-bound realities over our artificial and externally-imposed mathematical models of their realities” [2]. Thus, naturalistic inquiry, which is to explore "multiple and constructed realities", is suitable for the purpose of this study-exploring the "multiple and constructed realities" of insiders and outsiders regarding the role of principal and leadership development. The methodology is primarily exploratory and descriptive, with the intent to generate a clear, accurate portrayal of the perceptions of one group in a particular context, without looking for a generalizable conclusion. Based on individuals' experiential knowledge, the purpose of the study is not to predict or control, but to achieve "some level of understanding". The study is influenced by the values of the researchers, the participants and the context, since "inquiry is valuebound” [3] .

\section{Data Analysis}

The researchers designed a questionnaire with five semi-open questions based on the topics discussed in the training program by Canadian trainers and Chinese trainees. These topics included the principal's role in student achievement and leadership development. Participants in the study were asked to answer the five questions in writing. Five participants among them voluntarily accepted a face-to-face interview with the researcher individually. Personal background of the participants was considered - school, gender, age, and position -to determine whether any of these factors would influence perceptions.

\subsection{Leading actions of a leader}

The first question, "How do you define leadership? What kind of competencies relate to the leadership of a Chinese principal?” represents a classical question in the leadership field. The purpose of the question was to find out the differences and similarities between the perceptions of Chinese principals compared with the Ontario Principal Leadership Framework in terms of leadership and competencies.

In the Chinese language, the word "leadership" expresses two meanings: the first means "leader", the second means "leading actions of a leader". A group of participants explained leadership with the first meaning - as a leader, and considered the leader as an organizer, a commander, an overseer of a school. The second group stated leadership with the second meaning-leading actions of a leader, and defined leadership as actions of leading, guiding and serving.

Concerning leadership competencies, participants put forward many different competencies from different levels and viewpoints, such as abilities of predicting, arousing, decision-making, organizing, implementing, collaborating, communicating, studying, team-spirit, affinity, perseverance, passion, devotion, and charm etc. But participants didn't logically and systematically address leadership competencies by sorting them into three categories -skills, knowledge and attitude -- that is the convention of the Ontario Principal Leadership Framework.

However, almost all concepts and competencies, which are mentioned in the Ontario Principal Leadership Framework, were also mentioned or discussed in the participants' questionnaires or interviews. From a theoretical level, this fact suggests that the perceptions and interpretations of Chinese principals regarding leadership and related competencies are quite similar to current western leadership theories, as evident within the Ontario Principal Leadership Framework.

\subsection{Leadership Competency}

As discussed above, theoretically most of the participants agreed with the Ontario Principal Leadership Framework in terms of leadership competencies. However, what are the key leadership competencies that participants valued most in real situations? The personal question, "Why are you a school principal? What kind of leadership competencies do you possess or lack? " was designed to encourage participants to connect themselves with leadership through a self-evaluation.

Generally, the participants gave themselves a higher-level evaluation with regard to leadership competencies, and considered themselves to possess most leadership competencies. As they sorted out the reasons for becoming principals, four factors stood out distinctively: excellent subject teaching, devotion and diligence, maintaining good relationships and coordinating ability.

However, as they discussed leadership competencies that were lacking, differences in choices became apparent. Some participants regretted a lack of theoretical background in education, some thought their studying and research abilities needed to be improved, some wanted to 
sharpen their communication skills; and some wished to cultivate their innovating ability.

Among 40 participants, only three were female, and all vice principals. In their perceptions they lacked courage and confidence in authority, creativity and innovativeness. This kind of perception is quite different from that of male principals. Concerning gender, during the training program, the researchers frequently heard questions from the participants about why there were so many female principals and vice principals in Canadian schools? In this training program, among 81 Chinese trainees, there were only 6 females, only one of which was a principal. Gender imbalance appears to be a very serious question for Chinese principal ranks.

\subsection{Leadership Development}

The question "How to develop leadership in a principal?” led to demands by Chinese principals for leadership development training and better design and organization of future programs.

Most participants thought of leadership development as a long-term and sustaining process, requiring consistent study, practice and reflection, and attendance at various training workshops. It also required an effective principal evaluation system to ensure appropriate motivation. Some participants suggested designing and implementing a principal development plan to promote self-improvement. Some participants proposed to draw ideas from the Ontario's Principal Qualification Program to make the position of principal more professional. Some participants also suggested strengthening exchange and communication among principals in China, and between China and other countries.

\subsection{The role of Chinese school principal in promoting student achievement}

In the researchers' judgment, the question 'How do you think the role of a Chinese school principal relates to student achievement?" is a very westernstyle question. In Chinese culture, the role of a leader/principal is usually connected with his/her organization/school, in keeping with a Chinese saying "A good principal is a good school". Normally in Chinese culture the role of a principal is not directly connected with student achievement. Thus, the purpose of this question is to challenge the traditional thinking of Chinese principals. The idea of directly connecting the role of the principal with student achievement is borrowed from the Ontario Principal Leadership Framework. The researchers had hoped, when the participants answered the question, that the principals would visualize the individual faces of their students, not just school building infrastructure or a blurred picture of the whole school student body, or even exam papers or test scores. Forty participants answered the question.

Most participants addressed their opinions about the role of a Chinese principal in student achievement from two levels. From an institutional level, many participants considered a principal as an overall planner, a decision-maker, a leader, a guide and a supervisor. Through various schemes and plans of teacher development, curriculum design, school administration, and school culture development etc., a principal should lead people in his/her school toward a shared vision of all-round and life-long development. For each student in the school, an implementation plan must be developed. From a more personal and individual level, many participants viewed the principal as the soul of a school, a teacher of all teachers, a teacher and guardian of each student. He/she is a model to students as well as an educator. Through action or word the principal will change and influence student development unobtrusively and imperceptibly.

From a practical perspective, many participants discussed whether Chinese principals actually play the theoretical roles mentioned above. One participant said: "In China, a principal is a general of a school who has to take care of everything and who spends most energy and time not on students but on external coordination.” Another participant said: "Chinese principals play roles as a nanny and a housekeeper. Under the administrative control of government, a principal doesn't have much autonomy in running a school. Under pressure from the National Entrance College Examination (NECE), a principal has to push teachers to take most student -related time for NECE preparation.. " Many participants observed that the NECE is currently one of the most important assessment indicators for school education in China. This fact forces principals to put too much emphasis on examinationoriented education, and to pay less attention to the student's all-round development. This emphasis is especially damaging for those students who have difficulties in learning. All participants agreed that principals should take more care with those students who experienced academic failures and difficulties, and let each student in school taste success. They have already seen hope for this type of change. The New Curriculum Reform, which is currently being carried out in China, will encourage teachers and principals to pay more attention to individual demand and individual development through various changes in curriculum arrangements and teaching methods. 


\subsection{Chinese and Canadian principals working towards student achievement}

The question "What are the differences and similarities between Chinese principals and Canadian principals in working towards student achievement?” intended to help participants to clarify their thoughts through a comparative study, with Canadian principals as a reference. Participants belabored this question. With only three weeks' observation and discussion during their Toronto training program, the perceptions of the Chinese principals with respect to their Canadian colleagues cannot be definitive or comprehensive. Furthermore, with the limitations of time and language, many of their perceptions and observations stopped at the theoretical level. However, their experiences and insights, perceptions, opinions, and interpretations are worth pondering.

At the beginning, the participants took much time and energy to address the differences between the two jurisdictions. Related causes were also discussed, and eight kinds of differences emerged.

First, unlike the Canadian principal, a Chinese principal follows a strong executive model. He or she is a government officer, because a school in China is a government-sponsored institution and considered as an extension of government. The school is strongly controlled by local and national governments, and compared with their Canadian counterparts, Chinese principals have much less autonomy.

Second, Chinese principals are appointed directly by executive orders of local government. Appointments are based mostly on excellent performance in teaching. In China there is not a normative process of appointing a Canadian principal based on a professional standard such as Ontario Principal Qualification Program. To a significant extent, a Chinese principal is only responsible to higher-level officials, is less likely to get support from society and government, and does not necessarily enjoy a supportive environment.

Third, unlike their Canadian colleagues who can focus on education and school administration, Chinese principals have to deal with too much external interference from government and society. A Canadian principal acts as a cultural role model, an academic person and an educator, but a Chinese principal acts more like a general manager, a government officer and a diplomat.

Fourth, unlike a Canadian principal who can usually put into practice any reasonable education philosophy, a Chinese principal has almost no space to try his/her own educational ideas because of the heavy pressure related to the National Entrance
College Examination. While Canadian principals care much more about graduation rates, Chinese principals have to emphasize college entrance success.

Fifthly, Chinese principals joked about being under three mountains: funding, security and teaching quality. Raising funds is a headache, yet one of the most important things for a Chinese principal running a school. A school's fate, as well as staff salary and welfare, are all related to this ability to raise funds. Ontario principals don't need to worry too much about funding since financial support comes down from government to the local school board and then the school. The principal in Ontario enjoys reasonable autonomy, and can focus on education quality.

Sixth, a principal or a vice principal in Canada is a professional administrator who may focus on administration without a teaching workload. A principal or vice principal in China enjoys an executive position, with honor and preferential treatment. But besides carrying out all duties, the principal or vice principal may have to assume a teaching workload, and also play other roles such as politician and social activist with unlimited duties.

Seventh, because of relatively smaller schools and class sizes, Canadian principals have less work pressure and enjoy more happiness and success from their positions. But their Chinese colleagues have to deal with serious challenges from excessively enlarged school size, crowded classrooms, complicated relationships and multiple roles.

Eighth, compared to their Canadian counterparts, Chinese principals have to work longer hours without regular weekends or holidays. And their salary and benefits are much lower than their Canadian colleagues.

In the light of these eight differences, some of the Chinese program participants complained that it is difficult to be a principal in China. It is even more difficult in China to be a prominent principal in a key school. Comparing Chinese principals to Canadian principals, some participants pointed out that the pressures of external affairs required of the former causes a significant difference in job performance.

Finally, the participants recognized that both principals of China and Canada have played important roles in the education development of their countries and that there were many similarities; principals in both cultures take charge of school administration, try their best to improve education quality, take responsibility to educate students, and for the most part are excellent teachers. In exercising their responsibilities they demonstrate passion, persistence, devotion and confidence towards education and students. Principals are the 
soul of a school and shoulder very heavy burdens. In so doing, principals enjoy high respect and a solid reputation with society. Principals also undertake, on behalf of government and the nation, to educate the future citizens of the community, and to cultivate human beings equipped with international vision and worldwide humanity. In a word, under the different systems, principals of both China and Canada serve the same purpose and strive to complete their missions in their own appropriate ways.

\section{Conclusions}

Through above five questions, Chinese principals have presented their perceptions, opinions, and interpretations regarding the role of principal and leadership development. A relatively concrete picture of a principal's role in a Chinese school can be envisaged. From this picture, and a deeper understanding about the role of a principal in China, some suggestions and comments from the researchers can be presented.

Regarding theory on leadership and competency, Chinese principals have exhibited knowledge of administration and leadership but their perceptions did not show logical and systematic understanding as set out in the Ontario Framework. A leadership seminar is needed to help them understand leadership theory.

The participants' high self-evaluation about their own leadership demonstrates their confidence in their own position and abilities. However, the deficiencies in leadership competencies identified by themselves -- such as education theory, study and research ability, communication skills, and creativity - demonstrate the need for training workshops focused on skill, knowledge, and attitudes.

From the delegation group structure, gender imbalance is apparent. Female principals also show no confidence in their leadership. Based on extensive research results, in an educational organization, gender balance is important. A female principal not only benefits the educational organization itself, but also encourages female staff, especially female students, by setting a good example. China should learn from Canada and build up supporting systems to encourage and train more and confident female principals.

Chinese principals appreciate the theory underlying the Ontario Principal Leadership Framework, especially that the leadership of an active principal is essential in improving student achievement. However, in reality, Chinese principals complain that National Entrance College Examination has distorted the nature of education and restricted principals' capacity to enhance quality.
As well, excessive outside interference has adversely influenced normal educational sequences, and too much external coordination wastes a principal's time and energy. Such factors all result in less attention to student achievement and all-round development. How to play an effective role in student achievement, is not just a principal's duty but is a system issue that demands the supports of the whole society -including governments, schools, parents and community.

The professionalization of the principal position in Canada impressed many participants. Setting up a professionalized standard such as the Ontario Principal Qualification Program and strengthening related training might be an effective way to improve educational leadership in China.

\section{References}

[1] The Institute for Education Leadership Ontario, "Putting Ontario's Leadership Framework Into Action: A Guide for School \& System Leaders”. www.educationleadership-ontario.ca.

[2] Lincoln, Y. S., "Naturalistic Inquiry (Chinese Version) ", Preface, translated by Yang, X. \& Lin, J., Scientific and Technological Publishing House, Beijing, China, 2004, P2.

[3] Lincoln, Y. S., \& Guba, E.G., "Naturalistic Inquiry", Thousand Oaks: Sage Publication, Inc. 1985, P37. 